\title{
Origem de classe e chances de vida no Brasil
}

\author{
José Alcides Figueiredo Santos \\ Universidade Federal de Juiz de Fora, Brasil \\ (iD) https://orcid.org/0000-0003-2606-7150 \\ josealcidesf@yahoo.com.br
}

Investiga-se as relações entre origem de classe e chances de vida no Brasil com os dados de mobilidade social da PNAD 2014. O estudo interessa-se pela questão das desigualdades de chances de vida e de resultados obtidos e, por isso, utiliza como medida de realização socioeconômica os rendimentos dos filhos. Combina-se medidas baseadas em empregos na origem familiar e de rendimentos no destino. $\mathrm{O}$ trabalho expande e complementa investigação anterior que usou medidas de classe social baseadas em empregos e focalizou a influência da origem no destino ao topo social dos empregos mais privilegiados (FIGUEIREDO SANTOS, 2019). O uso de medidas diferenciadas de resultados, como a renda no destino, parece novo ou pouco comum na literatura sociológica de mobilidade social no país. Realiza-se investigação diferenciada em termos classificação socioeconômica, estratégicas de pesquisa e modelos estatísticos empregados visando captar diferenças entre os grupos em meio aos impactos das mudanças estruturais nas relações entre origem e chances de vida. 
As relações entre origem e destino são estudadas com modelos de regressão que são sensíveis às mudanças estruturais que afetam a distribuição dos fatores influentes. Isto significa que o interesse deste estudo é na mobilidade social que emerge sob a ação em particular do jogo entre expansão educacional e mudança da estrutura do emprego. Não está sendo tratada aqui a questão da mobilidade relativa ou fluidez social. ${ }^{1} \mathrm{Na}$ literatura tem sido repensado o interesse excessivo na “fluidez social” em prejuízo da atenção ao impacto das mudanças estruturais no regime de mobilidade social (BREEN, LUIJKX, 2004, p. 402). Servem de referência para o estudo as orientações de um novo projeto comparativo internacional na área que se interessa pelas consequências para a mobilidade social do jogo entre mudanças estruturais (BERNARDI, BALLARINO, 2016a). De maneira especial, o trabalho referido debruça-se sobre a associação entre origem e destino não mediada pela educação ou, dito de outro modo, da associação socioeconômica intergeracional entre pessoas do mesmo nível educacional. A literatura internacional de mobilidade social tem dedicado menos atenção à análise o efeito direto da origem social no destino, ou seja, a associação entre o status socioeconômico dos indivíduos e dos seus pais, independente da realização educacional individual. A noção de que a educação seria o grande equalizador social requer que a associação direta entre a origem e destino, após controlar a aquisição educacional, seja igual ou perto de zero ao longo do tempo (BERNARDI, BALLARINO, 2016b, p. 2-4).

1. Este artigo focaliza o que ocorrre na relação entre origem e destino social quando são consideradas as implicações das mudanças estruturais. Já as taxas relativas de mobilidade social captam as "as chances de indivíduos de diferentes classes de origem serem encontrados em diferentes classes de destino quando todos os efeitos da mudança estrutural de classe são descontados”. Neste sentido elas estão "relacionadas à associação líquida (net) — a rigidez inerente — que existe entre as posições de classe dos filhos e seus pais”. (GOLDTHORPE, 2016, p. 96). 
O triângulo analítico formado pelas associações entre origem social, educação e destino (OED) pretende representar o processo básico subjacente à reprodução intergeracional da desigualdade. O conjunto do processo envolve, então, a associação entre a origem e a realização educacional (O-E), a associação entre a educação e o destino (E-D), que afere os retornos socioeconômicos da educação e, por fim, a associação direta entre a origem e o destino (OD), ou seja, a associação que não é mediada pela realização educacional (GOLDTHORPE, 2016, p. 101-102). O estudo da mobilidade entre gerações, no sentido geral, procura mensurar o grau de associação que existe entre a condição econômica dos pais e dos seus filhos adultos. Quanto mais forte a associação menor é a mobilidade. Uma associação baixa significa que a trajetória dos indivíduos varia de forma independente da origem social. Em uma perspectiva de classe, a mobilidade intergeracional diz respeito aos padrões de associação que existem entre as circunstâncias de classe em que os indivíduos foram criados ("origem de classe”) e a sua condição de classe atual (o "destino de classe”) (TORCHE, 2015b). Neste estudo o efeito da origem de classe no destino social está sendo conceituado em termos de chances de vida, ou bem-estar socioeconômico, e mensurado pela renda que os filhos obtêm nas circunstâncias atuais. Max Weber cunhou a expressão chances ou oportunidades de vida ao pensar a noção de classe social como um "componente causal específico” que permite entender as possibilidades e os limites colocados aos indivíduos pela ordem econômica (WEBER, 2004, p. 176). Embora o presente estudo se oriente por uma abordagem neomarxista do "componente causal específico" de classe social, a expressão chances de vida enfatiza as consequências amplas da origem ou condição de classe para o horizonte de vida das pessoas.

$\mathrm{O}$ artigo coloca para o Brasil as quatro principais questões de pes- 
quisa do projeto comparativo internacional mais recentemente desenvolvido na área de mobilidade social (BERNARDI, BALLARINO, 2016a). Foi incluída uma questão adicional que vem aqui em segundo lugar. O estudo organiza-se em torno de cinco questões de pesquisa: 1) Persiste uma associação direta entre origem de classe e recompensa de renda além do efeito mediado pela educação? 2) Persiste um efeito direto da origem na renda sem ser mediado pela educação e pela posição de classe adquirida? 3) A associação intergeracional líquida (o efeito direto da origem na renda) declinou no tempo entre as coortes? 4) A associação intergeracional varia por níveis de escolaridade ou, dito de modo mais específico, o efeito da origem social na renda dos filhos é menor entre os indivíduos mais educados? 5) A associação entre a educação adquirida e a realização de renda (os retornos da educação) tem variado no tempo?

\section{Evidências internacionais e para o Brasil}

O mais recente projeto comparativo internacional sobre a reprodução intergeracional da desigualdade examinou em 14 países desenvolvidos as relações entre origens sociais dos indivíduos e os seus resultados ocupacionais e rendimentos, ao longo do tempo e entre diferentes níveis de ensino. Foi constatada uma associação intergeracional direta na renda, após o controle da realização educacional, em todos os países estudados. A redução do efeito bruto e o efeito líquido da origem na renda, quando se controla a educação, são da mesma ordem que a encontrada com o uso do índice socioeconômico internacional de status das ocupações (ISEI - International Social-Economic Index of Occupational Status) (BALLARINO, BERNARDI, 2016, p. 258). Na avaliação da tendência temporal na sucessão das coortes, quando 
se considera o ISEI como resultado ocupacional, em quase todos os países estudados o efeito direto da origem não decresce entre coortes ou períodos. O efeito do ISEI dos pais na renda dos filhos é mais variável entre os países tornando o padrão geral menos claro. Permanece estável na Holanda, Reino Unido, Noruega e entre as mulheres no Japão; decresce na Suécia, Israel, França e entre os homens no Japão. Quando a origem é medida pela renda dos pais, o efeito na renda dos filhos aumenta na Rússia, Hungria e ligeiramente na Noruega (BALLARINO, BERNARDI, 2016, p. 260-1).

A pesquisa de estratificação social tem constatado um efeito positivo da origem social na realização ocupacional e de renda, mesmo quando se controla a realização educacional. Esta persistência do efeito da origem social ao ser controlada a educação do indivíduo, demonstra que os antecedentes familiares influenciam o sucesso socioeconômico da pessoa não apenas através do sistema educacional, mas também no mercado de trabalho ou através da transferência de capital entre os autoempregados (ERIKSON, JONSSON, 1998, p. 1920). Além disso, parece válido supor que o efeito da origem de classe na renda tende a desaparecer, ao ser controlada a posição de classe atual, na medida em que se considere que a renda é ligada predominantemente às posições (ERIKSON, JONSSON, 1998, p. 27). As posições de classe, quando mensuradas ao nível da estrutura do emprego, dizem respeito às características das relações e condições de emprego que em certa medida independem dos atributos das pessoas que as ocupam. Tendo sido controlada previamente a mediação do fator educacional, essa formulação pressupõe que o efeito da origem de classe sobre a renda dos filhos seria mediatizado essencialmente pela aquisição da posição de classe atual. Entretanto, tal efeito pode se dar de forma direta, sem ser mediatizado seja pela educação seja 
pela posição de classe adquirida. $O$ fato do efeito de origem persistir com o controle de educação e mesmo da classe de destino pode ser visto como uma indicação de que classe tem efeitos de múltiplos modos, que várias formas de recursos e barreiras se cristalizam na classe social (ERIKSON, JONSSON, 1998, p. 34).

A questão geral do papel da educação como o grande equalizador social tem sido recolocada nos últimos tempos olhando-se para níveis específicos de educação. Três interpretações sugerem a ideia de que a associação direta entre origem e destino seria tanto menor quanto maior o nível de educação alcançado. De um lado, postula-se que o mercado de trabalho para aquele altamente educado seria mais baseado no mérito do que em outros níveis educacionais. De outro lado, entende-se que aquele que atinge elevada educação, porém oriundo de uma origem mais baixa, representaria o resultado de uma seletividade positiva, baseada em habilidade e motivação, como condição mesma para a superação das barreiras enfrentadas. Além disso, considera-se que nas condições contemporâneas a influência dos pais diminuiria no curso do ciclo de vida entre aqueles que retardam o início da carreira em função de uma longa permanência na instituição educacional. Esta questão geral, no entanto, pode ser abordada de um modo diferente, como fez o referido estudo comparativo, focalizando-se a força da associação direta entre aqueles que não atingiram a educação superior. A origem social privilegiada poderia dar uma "vantagem compensatória”, na trajetória em direção ao destino, para aqueles filhos que não se saíram tão bem na realização educacional (BERNARDI, BALLARINO, 2016, p. 6).

Nos países desenvolvidos estudados no projeto comparativo internacional, quando origem e destino são mensurados pelo ISEI, regra geral a associação direta é maior entre os menos educados, confirmando 
para a maioria dos casos estudados a noção de vantagem compensatória. No caso da renda, em certo número de países, o efeito direto da origem é maior entre os mais educados e oferece inclusive uma vantagem adicional para quem está no topo da distribuição de renda. A origem social gera um efeito impulsionador, o que também coloca em dúvida a noção do papel equalizador da educação universitária. Estabelecem-se dois padrões de transmissão intergeracional de vantagem. Um padrão defensivo baseado na vantagem compensatória e um padrão ofensivo baseado no efeito impulsionador. Entretanto, parte da força do efeito da origem sobre a renda, quando comparada ao destino medido pelo ISEI da ocupação dos filhos, pode ser um produto da maior variância que se expressa na variável renda (BALLARINO, BERNARDI, 2016, p. 262-5).

No tocante à questão da variação dos retornos educacionais no tempo predominam na literatura as hipóteses de mudança tecnológica com viés de qualificação e de inflação de credenciais educacionais. Na primeira hipótese, entende-se que a mudança tecnológica reduz o valor de mercado dos menos qualificados. Na segunda hipótese, considera-se que o aumento da oferta rebaixa o valor sinalizador das qualificações para os empregadores. Ambos os mecanismos podem estar ativos ao mesmo tempo (BERNARDI, BALLARINO, 2016a, p. 7). Em muitos países estudados os retornos relativos da educação superior decrescem no tempo quando medido pelo ISEI ou o acesso à classe superior. Ao tomar a renda como resultado, as evidências são mais ambíguas. O prêmio da educação superior aumenta em alguns países (Hungria, Holanda, Rússia e Israel); declina em outros (Suécia, Franca e Noruega); mostra-se estável em outros três (Reino Unido, Alemanha e Japão). Estes padrões diferenciados parecem se relacionar com as especificidades de cada país no equilíbrio, ou desequilíbrio, 
existente entre a oferta e a demanda por qualificações. As variações nos retornos educacionais dependem crucialmente do jogo entre esta oferta e demanda (BALLARINO, BERNARDI, 2016, p. 267-268).

Usando uma tipologia de classes devidamente ajustada aos dados de origem social do suplemento de mobilidade social da PNAD de 1996, foram avaliados no Brasil os efeitos intergeracionais da origem de classe na aquisição educacional e na renda dos indivíduos. A origem de classe explica 25,8\% da variância da renda de todas as fontes ( $\mathrm{R}^{2}$ ajustado). O controle dos atributos de capital humano, notadamente a educação, faz com que os efeitos de origem se atenuem fortemente, sendo que em várias categorias de modo bastante pronunciado. Entretanto, o fato de se manter em torno de um terço do efeito de origem, confirma a operação de outros mecanismos através dos quais a família de origem influencia a realização socioeconômica dos descendentes. A posição de classe atual diminui o efeito da origem de modo tão significativo quanto o capital humano, sendo que em importantes categorias, em uma intensidade ainda maior. Constatou-se, por fim, que o controle conjunto da educação e da posição de classe adquirida, ao promoverem de forma extremamente forte a redução do efeito de origem na renda, revelam-se como os mais importantes fatores mediadores intergeracionais da realização de renda. Entretanto, persiste um ponderável efeito direto da origem na renda, ou seja, um efeito não mediado pelo sistema educacional e pela aquisição da posição de classe atual, após todos os controles (FIGUEIREDO SANTOS, 2002).

O nível de transmissão intergeracional de rendimentos estimado no Brasil está entre os mais altos observados do mundo. Estudo de Dunn (2007), ao analisar os ganhos ao longo da vida (lifetime earnings), estimou uma elasticidade de $85 \%$ em 1996. Isto significa que 
se as rendas dos pais diferem em $100 \%$, a renda dos filhos irá diferir, em média, em 85\%. A diferença proporcional de rendimentos entre os pais será replicada em um grau extremamente elevado (85\%) na geração dos filhos. Entretanto, estudo posterior estimou uma queda da elasticidade de renda de 0,734 em 1996 para 0,433 em 2008. Isto representa uma redução absoluta de 0,30 pontos percentuais ou relativa de $41 \%$. Tanto a herança de renda pura, quanto a herança de renda mediada pela educação, diminuiu ao longo do período estudado (RIBEIRO, 2017). Entretanto, parte desta redução pode estar superestimada, pois não foram usados ganhos ao longo da vida (lifetime earnings), que captam melhor a transmissão intergeracional de rendimentos, como foi demostrado por Dunn (2007).

O Brasil foi o primeiro país da América Latina a conduzir um levantamento de mobilidade social nacionalmente representativo no ano de 1973 em um suplemento da PNAD (TORCHE, 2014). O novo levantamento da PNAD de 2014, quatro décadas depois do primeiro e quase duas décadas do último realizado em 1996, representa uma oportunidade especial para investigar as relações dinâmicas que se formam entre desigualdade e mobilidade no Brasil. Não se trata apenas de enfatizar, em termos gerais, a relevância social e a importância para a compreensão da sociedade contemporânea dos estudos que tratam da reprodução intergeracional da desigualdade. As pesquisas realizadas a partir dos anos 90 no Brasil e na América Latina revelam contradições a respeito das relações entre desigualdade e mobilidade que estão a exigir esclarecimento. Estudos econômicos mostram que a desigualdade na América Latina está negativamente correlacionada com a mobilidade, ou seja, mais desigualdade se associa a menos mobilidade ou fluidez na transmissão intergeracional de vantagens. Entretanto, os estudos de mobilidade de classe social, ao contrário do 
que se esperaria, não mostram um grau de fluidez ou igualdade de oportunidades sistematicamente menor na América Latina do que em países menos desiguais do mundo desenvolvido. Trata-se de uma marcante contradição entre os resultados da mobilidade econômica e da mobilidade de classe, no caso do Brasil e da América Latina, que tem colocado em evidência, conforme revisão recente da literatura, a necessidade dos sociólogos da região reconsiderarem a forma de mensurar e abordar a mobilidade de classe social de modo a "fortalecer a sua contribuição nas conversações sobre a desigualdade econômica” (TORCHE, 2014).

\section{Métodos}

A noção de classe social foi informada por uma abordagem teórica neomarxista. Entende-se que as divisões de classe são constituídas por desigualdades de direitos e poderes sobre recursos produtivos que geram vantagens e desvantagens entre categorias. A variável independente foi mensurada por uma tipologia de classes ajustada às especificidades da estrutura social do país (WRIGHT, 1997; FIGUEIREDO SANTOS, 2005, 2010, 2014). Utiliza-se aqui uma versão compacta que diferencia cinco grandes agrupamentos de classe. O topo social é formado pelas três dimensões principais que geram privilégios, isto é, a propriedade de ativos de capital, o controle de conhecimento perito e o exercício de autoridade. O agrupamento abarca as categorias de empregadores, especialista autônomo, empregado especialista e gerente. São especificadas as posições de não empregadores detentores de menores ativos físicos de capital e de terra; dito de outro modo, de controladores de ativos de menor valor, ou generativos de menor valor econômico. Este agrupamento é formado pelas categorias de autô- 
nomo com ativos e de autônomo agrícola. Os empregados qualificados e os supervisores formam um segmento distinto no interior do trabalho assalariado em função de aproximações ou vínculos parciais com o exercício de autoridade e a posse de qualificações escassas. O trabalhador típico representa a categoria majoritária submetida plenamente aos processos conjugados de controle da atividade do agente e de apropriação dos resultados do trabalho. Por fim, diferencia-se um bloco de posições de classe destituídas de ativos por meio de processos que levam à exclusão, à insuficiência ou à depreciação de ativos geradores de valor. Compõe este agregado o trabalhador elementar, o autônomo precário, o empregado doméstico, o trabalhador de subsistência e o trabalhador excedente (desempregado). Não foi possível diferenciar o autônomo agrícola precário na classe de origem. A presença do pequeno empregador no topo social se deve ao fato de que não ter sido possível diferenciar os empregadores na origem pela dimensão do capital. Além disso, um estudo precedente revelou uma desvantagem ainda maior para quem tem origem inferior ao topo, em ter acesso ao topo social no destino, ao ser considerada uma dimensão ampliada de propriedade (FIGUEIREDO SANTOS, 2019). Na mensuração da classe de origem foi usado o critério de dominância considerando o emprego mais elevado entre os pais.

A variável dependente do estudo é a renda de todas as fontes dos filhos. A influência da origem pode ir além do emprego principal e da renda associada a ele. A desigualdade de recompensas por classe social de origem mostrar-se maior com o uso de medidas de renda mais inclusivas (HANSEN, 2001). Entretanto, os rendimentos apurados pelas pesquisas domiciliares fornecem uma medida de bem-estar baseada principalmente nas recompensas dos empregos. Nos limites deste escopo, a renda tem a vantagem de cobrir um sentido amplo de trans- 
missão ou redução das vantagens de origem. Deve-se estar ciente, no entanto, de algumas especificidades do uso da variável renda no destino. Os coeficientes para a variável independente tendem a ser tanto maior, quanto maior a variância da variável dependente. Este fato reflete a regra da regressão que vincula o tamanho dos coeficientes à variância da variável dependente. Existe mais variância na distribuição da renda, em comparação a outros indicadores socioeconômicos, no tempo e entre as rendas altas (BERNARDI, BALLARINO, 2016, p. 265). Quando há mais variação dentro do grupo no resultado, há mais espaço para a renda da pessoa no destino ser afetada por mecanismos de influência da origem (VANDECASTEELE, 2016, p. 233). Entretanto, em se tratando de pessoas empregadas, a depender dos arranjos institucionais que prevalecem no mercado de trabalho, a renda pode ter uma "base" abaixo da qual é menos provável ela cair, o que limita a sua variação. Por outro lado, em particular para certas categorias privilegiadas não existe um “teto” fixo ou, pelo menos, ele é mais flexível.

No presente estudo os efeitos da origem de classe social foram estimados sob a forma de médias preditas e diferenças proporcionais na renda com um Modelo Linear Generalizado (Generalized Linear Model), usando uma distribuição Gamma e uma função de ligação logarítmica. Da amostra analítica potencial de 27620 casos em 6\% deles a renda de todas as fontes é zero. A amostra analítica sem a renda zero possui 25977 casos com idade de 27 a 66 anos e informações válidas nas variáveis usadas nos modelos. A renda zero, como seria de esperar, está concentrada nas posições de trabalhador excedente (desempregado) e trabalhador de subsistência, que integram o agrupamento de posições destituídas de ativos. O Modelo Linear Generalizado com a função de ligação logarítmica oferece a vantagem de lidar com ze- 
ros, pois supõe que as médias são sempre positivas, mas não que todos os valores são positivos, como ocorre com a regressão padrão com a transformação logarítmica da variável dependente. A função de ligação faz a estimativa na escala transformada e gera a transformação de volta para a escala original ${ }^{2}$. No Modelo Linear Generalizado a função de ligação logarítmica usa o exponencial do preditor linear, ou seja, internaliza a transformação dentro do próprio modelo, em vez de fazer a transformação externa da variável dependente. Este procedimento permite fácil interpretação dos parâmetros estimados e dos valores ajustados (HARDIN, HILBE, 2012). O logaritmo do valor esperado de Y é diferente do valor esperado do logaritmo de Y. O exponencial do coeficiente do modelo Log-Normal padrão oferece informação sobre a média geométrica enquanto o modelo GLM sobre a média aritmética. A divergência entre as duas medidas pode ser ponderável (PETERSEN, 2017; BALDWIN, 2016, p. 561).

A distribuição Gamma é uma distribuição flexível para variáveis contínuas, apropriada para distribuições assimétricas, e incorpora o pressuposto de que o desvio padrão é proporcional à média (VITTINGHOFF et al., p. 315). “A distribuição Gamma é usada para modelar resultados”, explicam Hardin e Hilbe, "para os quais a resposta pode assumir somente valores superiores ou iguais a zero. (...) Idealmente o modelo Gamma é mais bem usado para respostas positivas que têm um coeficiente de variação constante. Contudo, o modelo é robusto mesmo na presença de grandes desvios deste critério”. (HARDIN, HILBE, 2012, p. 121). O modelo Log-Gamma, ponderam os especialistas, “é usado com dados nos quais a resposta é maior que 0" (HARDIN, HILBE, 2012, p. 129). Em função de dúvidas sobre o uso

2. Sobre este ponto levo em conta as observações de Nicholas J. Cox no fórum de discussão do programa Stata. Vide postagem: www.statalist.org. 
do modelo Log-Gamma com valores zero, os resultados foram apresentados para valores somente positivos. Esta escolha leva em conta também o fato de que nos modelos estimados com valores zero os resultados ficam bastante convergentes. Além disso, foram estimados modelos com a distribuição Poisson e os resultados ficaram também similares. Uma especificação exponencial com distribuição Poisson para a variável dependente contínua parece ser recomendável em várias situações quando se usa o Modelo Linear Generalizado (PETERSEN, 2017, p. 150). Todas as estimativas foram ajustadas ao desenho complexo do plano amostral da PNAD com o comando svy do programa Stata. As rendas médias preditas foram estimadas pelo margins do Stata. As estimativas sumarizam médias dos efeitos de todos os casos da amostra. Este efeito sumário da variável pode ser interpretado como o tamanho médio do efeito na amostra (LONG, FREESE, 2014, p. 245).

Elasticidade pode ser uma medida mais útil do que os efeitos marginais, pois não é influenciada pela escala em que a variável está medida. Semi-elasticidade é um híbrido de efeitos marginais e elasticidade, que mede a mudança proporcional em Y associada à mudança de uma unidade em X (CAMERON, TRIVEDI, 2009, p. 335). As diferenças entre as categorias foram representadas por discrepâncias proporcionais nos resultados. As medidas de diferenças proporcionais como a elasticidade, ao contrário das medidas de diferenças absolutas, não são influenciadas pelas diferenças entre as rendas médias (TORCHE, 2015a, p. 44; TORCHE, 2015b, p. 349). O uso de diferenças proporcionais, em vez de diferenças absolutas, contorna o viés que poderia decorrer da associação entre coorte, idade e perfis heterogêneos de idade-ganhos dos diferentes estágios na carreira ou no ciclo de vida. As medidas foram calculadas pelo comando margins do Stata 
usando opção eydx e depois transformadas em gráficos pelo marginsplot. A opção eydx estima a semi-elasticidade (mudança proporcional) no logaritmo do resultado (Y) para a mudança de uma unidade da variável independente. Nas variáveis independentes categóricas o efeito é computado como uma mudança discreta em relação à categoria de referência. O efeito é estimado em termos relativos, ou seja, em uma escala multiplicativa, sem equivaler exatamente a uma alteração percentual. Deve-se calcular o exponencial (ou antilog) para falar em aumento percentual usando a fórmula, p. $[\exp (\mathrm{Y})-1] * 100$. As duas escalas ficam próximas até 0,10 (10,5\%) ou mesmo 0,15 (16,2\%). $\mathrm{O}$ aumento percentual diverge progressivamente da semi-elasticidade na medida em que esta se torna maior.

Todos os modelos controlam por gênero, cor, coorte e Unidade da Federação (UF) onde o filho morava aos 15 anos. Esta última variável controla as diferenças pré-existentes no mercado de trabalho regional (HÄLLSTEN, 2013, p. 667-668). A educação é uma variável chave no estudo, na medida em que se pretende estimar a associação direta de origem e destino, ou seja, controlando pela educação individual. Torna-se necessário dispor de uma medida apropriada para evitar a superestimação do efeito líquido da origem. Distinguem-se na variável as principais transições educacionais que impactam nos destinos de classe: sem instrução, fundamental incompleto, fundamental completo, médio incompleto, médio completo, superior incompleto e superior completo. Na análise da associação intergeracional por níveis educacionais estes foram agregados em três categorias (médio incompleto, fundamental ou menos; médio completo ou superior incompleto; superior completo) visando captar efeitos interativos mais precisos.

Os gráficos estão sendo apresentados com os intervalos de confi- 
ança de 95\%. Entretanto, não caberia considerar que as estimativas são significativamente diferentes entre si somente se os seus intervalos de confiança não se sobrepuserem. O método de examinar a sobreposição dos intervalores de confiança, em comparação ao método padrão, rejeita a hipótese nula menos frequentemente quando ela é verdadeira e com mais frequência não rejeita a hipótese nula quando ela é falsa (LONG, FREESE, 2014: 297; SCHENKER, GENTLEMAN, 2001). Será usada a opção pwcompare(effects) do comando margins do Stata para contrastar os efeitos marginais de diferentes categorias, considerando a força das diferenças, os p-values e os intervalos de confiança gerados.

\section{Resultados e análises}

As duas primeiras questões vão ser tratas juntas em função do seu encadeamento e de comporem a mesma tabela. São apresentadas na Tabela 1 as rendas médias preditas somente com o modelo básico (Efeito Total) e com o controle adicional da educação dos filhos (Efeito Direto, ED) e depois com a agregação do controle da posição de classe adquirida pelo filho (EDC).

Primeira questão: Persiste uma associação entre origem e destino de classe social além do efeito mediado pela educação?

Segunda questão: Persiste um efeito direto de origem na renda sem ser mediado pela educação e pela posição de classe adquirida?

A origem no topo social se associa à obtenção de renda mais elevada pelos filhos. O oposto ocorre quando os pais tiveram uma origem destituída. O efeito direto da origem, não mediado pela educação, é bastante alto quando existem vantagens de origem. Entre quem tem desvantagens de origem ocorre um processo distinto, pois o efeito se 
aproxima ou ultrapassa 100\%. O aumento da renda após o controle estatístico sugere que a variável educação está atuando na direção contrária ao efeito da origem. Ocorre uma mediação às avessas, pois estas origens geram desvantagens educacionais. Isto significa que a renda dos filhos seria melhor se não fossem os limites da sua trajetória educacional. Já para a origem de trabalhador típico a trajetória educacional tem um efeito praticamente neutro na renda esperada. 
Tabela 1. Efeito da origem de classe na renda predita de todas as fontes em reais, total e direto, após o controle da educação (ED) e de classe (EDC), por gênero. Brasil, PNAD 2014.

\begin{tabular}{lccccc}
\hline Critério & Topo Social & Qual./Superv. & Pequ. Ativos & Trabalhador & Destituído \\
\hline Total Ambos & 4436 & 2984 & 1686 & 2039 & 1644 \\
Direto (ED) & 2940 & 2285 & 1933 & 2013 & 1899 \\
Direto (EDC) & 2629 & 2236 & 2003 & 2036 & 1966 \\
ED \% & 66,3 & 76,6 & 115 & 99 & 116 \\
EDC \% & 59,3 & 74,9 & 119 & 100 & 120 \\
Total Homem & 4855 & 3405 & 1879 & 2378 & 1905 \\
Direto (ED) & 3463 & 2760 & 2351 & 2489 & 2327 \\
Direto (EDC) & 2976 & 2568 & 2305 & 2396 & 2286 \\
ED \% & 71,3 & 81,1 & 125 & 105 & 122 \\
EDC \% & 61,3 & 75,4 & 123 & 101 & 120 \\
Total Mulher & 3851 & 2468 & 1439 & 1646 & 1332 \\
Direto (ED) & 2349 & 1769 & 1485 & 1518 & 1445 \\
Direto (EDC) & 2199 & 1836 & 1642 & 1628 & 1591 \\
ED \% & 60,1 & 71,7 & 103 & 92 & 108 \\
EDC \% & 57,1 & 74,4 & 114 & 99 & 119 \\
\hline
\end{tabular}

Obs: O Efeito Direto \% foi calculado pela razão: Direto/Total. 
O modelo com o controle adicional da posição de classe atual dos filhos, medida pela tipologia plena, impacta na mesma direção. A alteração não é forte por se seguir ao controle da educação. Ainda assim, as alterações são ponderáveis em três agrupamentos de origem. Parte da alteração se deve ao fato de estar sendo usada a renda de todas as fontes, no entanto, se sabe que grande parte da renda captada pela PNAD deriva da atividade principal. Não faria tanto sentido interpretar o fenômeno como se 59\% da renda da origem no topo social independessem totalmente da educação e do emprego adquiridos. Afinal, uma pessoa sem certo nível ou tipo de escolaridade e/ou emprego dificilmente teria uma renda bem mais elevada. O controle estatístico representa um tipo de exercício de manipulação dos dados para isolar uma associação de interesse. Estima-se aqui qual seria a renda média associada a uma dada origem social se fossem removidas as diferenças produzidas no resultado pelas variáveis controladas nos seus valores observados. Parece mais adequado considerar a origem como uma "garantia” de renda que permite encontrar os caminhos para a sua efetivação. Não se depende tanto de circunstâncias específicas e contingentes. $\mathrm{O}$ resultado em si destaca a força da herança social e sua capacidade de abrir caminhos para os filhos. Não se trata naturalmente de um processo inercial ou automático, que independe de ações defensivas ou ofensivas das partes interessadas, pois o potencial tem que ser efetivado em vantagem no mundo social. Entre as posições sem vantagens o processo se assemelha ao que já foi comentado no modelo com o controle adicional somente da educação.

As estimativas separadas por gênero revelam que os homens usufruem vantagens de renda em todas as origens. Nas origens mais vantajosas o efeito direto, não mediado pela educação, é alto em ambas as categorias, porém é menor entre as mulheres. Isto sinaliza a maior im- 
portância para elas da mediação educacional. No topo social e no empregado qualificado a agregação do controle de classe social aproxima os efeitos diretos de origem em um elevado patamar. Nesta situação, quando ambas as variáveis são controladas, a herança social parece importar igualmente para homens e mulheres. Um fator contrabalança o outro ao atuar em direção distinta, já que enquanto categoria a mulher tem maior escolaridade e o homem melhor emprego. Nas demais categorias de classe as diferenças são também aproximadas, porém devido às desvantagens de educação e emprego que compartilham.

Terceira questão: 3) A associação intergeracional líquida, ou seja, o efeito direto da origem, declinou no tempo entre as coortes?

A análise é conduzida confrontando-se a evolução do efeito total da origem de classe (Gráfico 1) e do efeito direto da origem (Gráfico 2) na renda. Foram estimados termos interativos entre origem de classe e coorte. São consideradas quatro coortes em intervalos de dez anos. Na base do gráfico “48” representa os nascidos de 1948 a 1957 e assim por diante. Estima-se a semi-elasticidade (mudança proporcional) da renda em relação à origem de classe. Realiza-se um contraste com a base social formada pela agregação do trabalhador típico e das posições destituídas. Trata-se de uma comparação amplamente representativa, de enorme peso demográfico, e que abarca inclusive um amplo contingente de trabalhadores em melhores circunstâncias na geração anterior. A linha onde está o valor zero equivale à ausência de diferença em relação a este agrupamento de referência. No texto os efeitos vão ser referidos no logaritmo do resultado, pois os gráficos foram gerados assim, com base nos efeitos previamente estimados. Para saber a diferença percentual deve-se usar a fórmula: $[\exp (\mathrm{Y})$ $1] * 100$.

A vantagem total de classe da origem no topo mostra-se estável 
entre as coortes quando confrontada com a base social (Gráfico 1). A vantagem proporcional varia de 0,816 na primeira coorte a 0,803 na última dentro do intervalo de confiança. Registra-se somente uma "retração" sem valor estatístico de -0,0129 dentro um intervalo de confiança entre -0,1905 e +0,1646. Na última coorte mantém-se uma vantagem relativa de $123 \%$ em comparação à origem na base, fazendo a conversão pela fórmula referida na parte de métodos. Nas coortes intermediárias as diferenças chegam mesmo a se ampliarem, porém se tornando menos precisas. As diferenças estão diminuindo para a origem de empregado qualificado e supervisor. As estimativas são menos precisas nas duas primeiras e mais precisas nas duas últimas coortes. O sentido geral parece ser de queda. Para a origem de controladores de pequenos ativos, possivelmente ao incluir de forma indiferenciada os autônomos agrícolas, inclusive aqueles mais precários, as médias preditas de renda se mantêm abaixo da base social embora mostrem uma aproximação entre as coortes.

As vantagens diretas do topo social, em relação à base social, quando controlada a mediação educacional, não revelam tendência de queda entre as coortes (Gráfico 2). Entre a primeira e a última coorte ocorre uma "redução" igualmente sem valor estatístico de -0,0062 com intervalo de confiança entre -0,1463 e +0,1411. Nas coortes intermediárias as vantagens chegam mesmo a aumentar. Na origem de empregado qualificado e supervisor ocorre entre a primeira e a última coorte uma "queda” da vantagem de $-0,0180$, estatisticamente descartável, considerando também o valor ínfimo da alteração dentro do intervalo de confiança entre -0,1656 e +0,1296. Regra geral os efeitos diretos são menos precisos. Para ambos os grupos não há tendência de redução do efeito direto de origem. Isto significa que não aumentou o papel mediador da educação nesta comparação. 


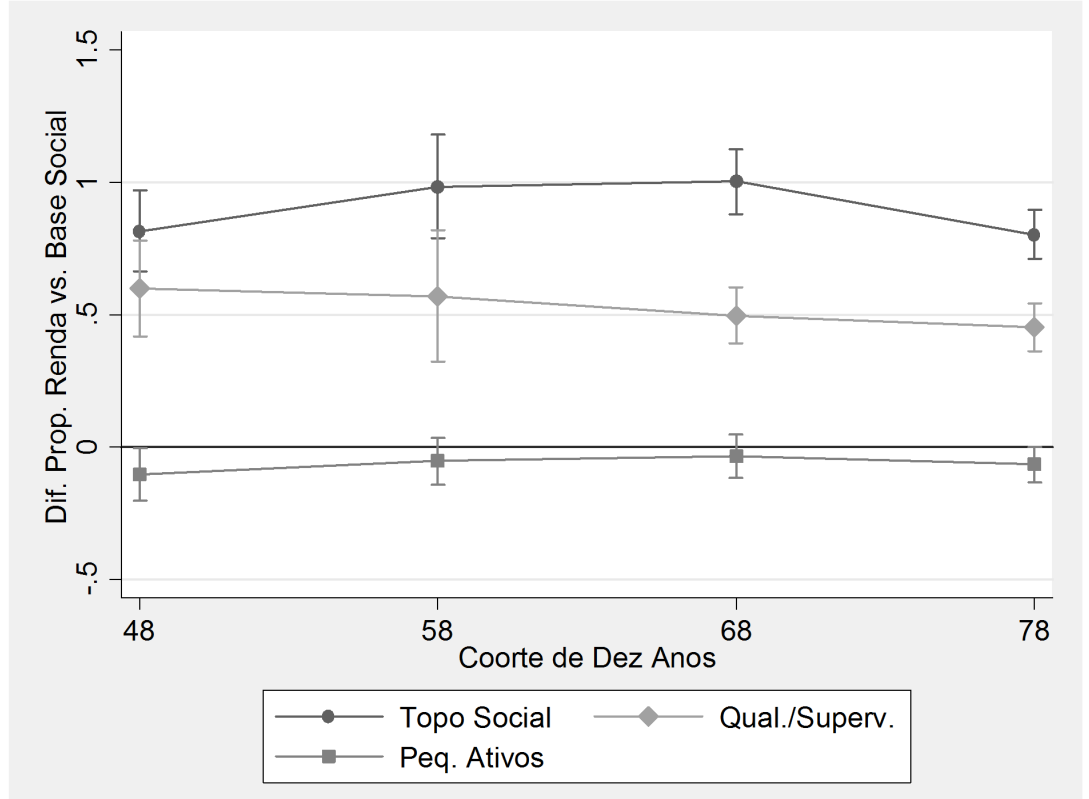

Gráfico 1. Diferença proporcional de renda (efeito total) da origem de classe em relação à base social, por coorte, com intervalo de confiança de $95 \%$

Ao contrastar os efeitos marginais das categorias confirma-se que nos dois critérios as vantagens do topo social em relação à base social não se atenuaram no tempo. Nos efeitos total e direto ocorre uma variação ínfima entre a primeira e a última coorte que não têm nenhum valor estatístico. $\mathrm{O}$ efeito direto por coorte foi estimado supondo que os retornos da educação são equivalentes entre as coortes, seguindo o procedimento do estudo comparativo de referência (BERNARDI, BALLARINO, 2016a), pois não foram introduzidos termos interativos entre as duas variáveis. Foi estimado, então, um novo modelo com o acréscimo de uma segunda interação entre coorte e educação, mantendo-se a interação original entre origem de classe e coorte. Ao 


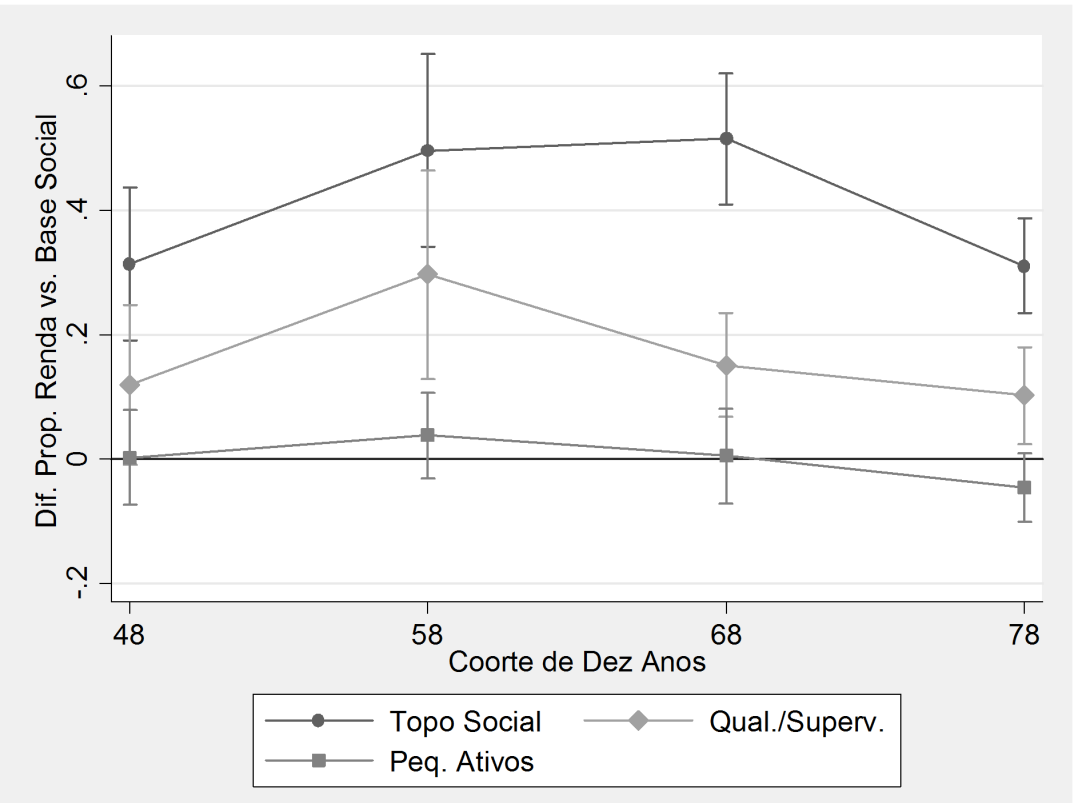

Gráfico 2. Diferença proporcional de renda (efeito direto) da origem de classe em relação à base social, por coorte, com intervalo de confiança de $95 \%$

se permitir que os retornos na educação variem entre as coortes, o modelo mostra um aumento da vantagem proporcional da origem no topo social de 0,1219 entre a primeira e a última coorte, com intervalo de confiança entre $-0,0301$ e $+0,2740$. Esta estimativa adicional sinaliza uma provável ampliação temporal da vantagem do topo.

Quarta questão: A associação intergeracional varia por níveis de escolaridade ou, dito de modo mais específico, o efeito de origem social é menor entre os indivíduos mais educados?

No Gráfico 3 são vistas as diferenças proporcionais (semi-elasticidade) na renda em relação ao destituído por três níveis de escolaridade. Foi estimada uma interação entre origem e educação. O valor 


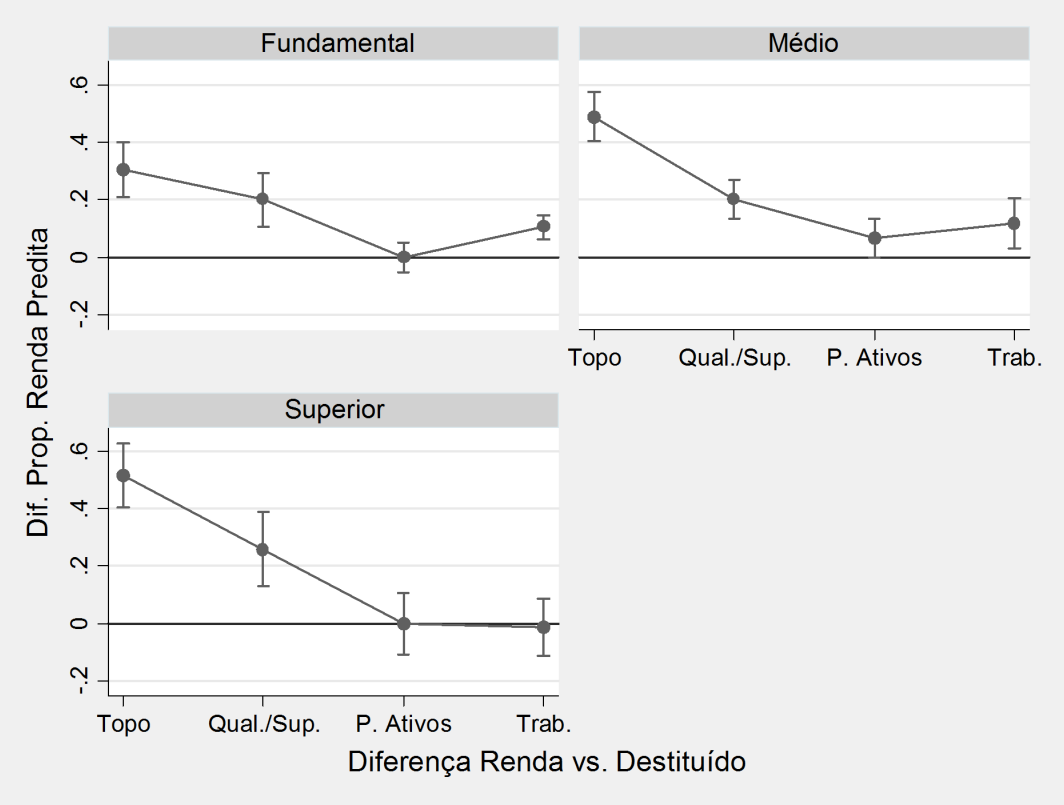

Gráfico 3. Diferença proporcional de renda da origem de classe em relação ao destituído, por nível educacional, com intervalo de confiança de $95 \%$

zero na linha que corta o gráfico equivale à ausência de diferenças. Não estão sendo consideradas aqui as diferenças de aquisição educacional entre estas origens que podem ser bastante marcantes. A questão aqui é o que corre com o efeito de origem quando as situações educacionais são equiparadas.

A vantagem da origem no topo social é maior para quem tem curso superior completo $(0,5163)$, embora seja também alta no médio completo $(0,4894)$. Em quem possui menor nível de escolaridade (média incompleta, fundamental ou inferior), denominada no gráfico de "Fundamental”, o efeito de origem no topo social ainda assim mostra um patamar marcante $(0,3041)$. Em qualquer um dos três níveis de esco- 
laridade a origem no topo mostra uma força especial. A escolaridade não age como um fator equalizador. A escolaridade superior em interação com a origem impulsiona ou potencializa a renda. Além disso, os que realizam uma aquisição educacional limitada, vindo desta origem, obtêm ainda assim uma vantagem apreciável em relação ao grupo destituído. Ao usar a distribuição Poisson, sem a renda zero, a estimativa para o superior completo, embora seja convergente, apresentou uma diferença relativamente menor e um intervalo de confiança maior.

A origem de empregado qualificado mostra vantagens de renda em relação ao destituído nos três níveis de escolaridade. Entretanto, as diferenças são menores e incertas quando são comparados entre si os próprios níveis educacionais - fundamental $(0,1999)$, médio $(0,2015)$ e superior $(0,2580)$ - , considerando os intervalos de confiança. A diferença entre o curso superior e o fundamental é de 0,0580, porém com intervalo de confiança entre -0,1021 e +0,2182. Na categoria de empregado qualificado o efeito de origem pode não ser tão forte e/ou a educação superior pode conter parte deste efeito neutralizando, no entanto, somente as distinções entre os níveis educacionais na força do efeito de origem. Nas duas comparações de classe restantes o curso superior completo anula as diferenças proporcionais de renda. Entretanto, a origem de trabalhador típico mantém vantagens nos demais níveis de escolaridade. Já na origem de pequenos ativos a vantagem de classe parece existir na escolaridade média, mas com certa incerteza. A educação superior equaliza a situação dos grupos no destino, em termos da renda obtida pelos filhos, somente quando as diferenças de origens são menores.

Quinta questão: A associação entre educação dos indivíduos e seus destinos de renda tem variado entre as coortes, ou seja, o retorno da educação tem aumentado ou diminuído no tempo? 
No Gráfico 4 são estimadas as diferenças proporcionais na renda por níveis educacionais entre as coortes. O modelo controla pela origem de classe e estima interações entre coorte e educação, seguindo o mesmo procedimento do estudo comparativo internacional (BERNARDI, BALLARINO, 2016a), de modo a isolar melhor as mudanças nos retornos da educação entre as coortes, sem a contaminação das desigualdades de origem. Educação é um fator importante na persistência intergeracional da desigualdade apenas se tiver um efeito direto em empregos, recompensas e outros resultados após controlar por origem e habilidades cognitivas (HOUT, 2012). Como não é possível controlar por habilidades cognitivas, o efeito em particular da educação superior estaria superestimado. São comparados os níveis maiores com o menor (médio incompleto, fundamental ou inferior). Os retornos da educação superior estiveram estáveis nas duas primeiras coortes, porém entraram em queda nas duas últimas coortes. As diferenças eram de 1,4578 no logaritmo do resultado na primeira corte e caíram para 1,1101 na última coorte. Ocorre uma retração desta vantagem proporcional em -0,3476 entre a primeira e a última coorte, com intervalo de confiança entre -0,4633 e -0,2322. Isto representa uma queda relativa de $23,8 \%$ no logaritmo do resultado $(0,3476 / 1,4578)$. Já os retornos da educação média estiveram estabilizados nas duas primeiras coortes, no intervalo de confiança, caíram na terceira e se estabilizaram neste patamar menor. As diferenças eram de 0,6155 no logaritmo do resultado na primeira corte e caíram para 0,3780 na última coorte. A retração da vantagem proporcional foi de -0,2375 entre a primeira e a última coorte, com intervalo de confiança entre -0,3551 e $-0,1199$. O resultado corresponde a uma queda relativa de 38,6\% $(0,2375 / 0,6155)$. Embora a redução tenha sido marcante nos dois grupos, a queda relativa da vantagem proporcional foi maior no ensino 
médio.

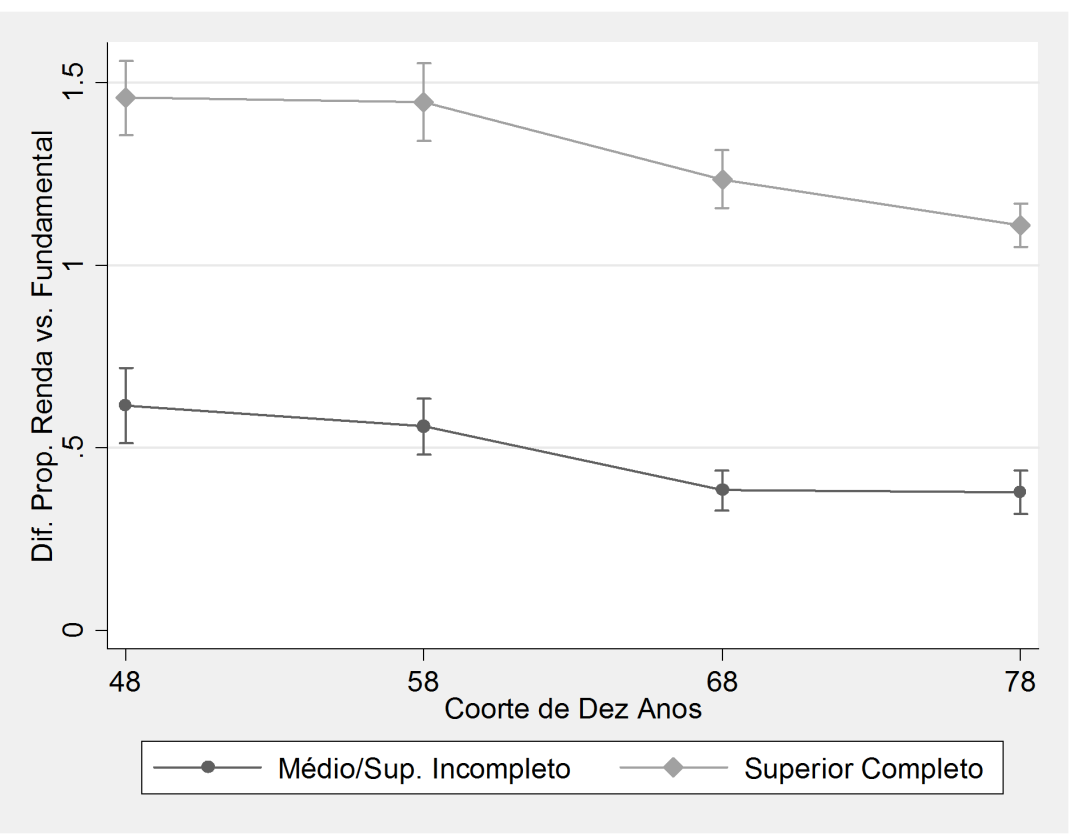

Gráfico 4. Diferença proporcional de renda entre níveis educacionais, por coorte, com intervalo de confiança de $95 \%$

O Gráfico 5 revela o que ocorre com os retornos proporcionais considerando que eles possam variar por origem de classe e coorte. Utiliza-se uma interação tripla entre origem de classe, coorte e educação, o que representa uma opção nova não explorada no estudo comparativo internacional (BERNARDI, BALLARINO, 2016a). Os efeitos interativos removem o constrangimento estabelecido pelo modelo de efeitos aditivos ou equivalentes entre as diferentes origens e níveis educacionais. Os efeitos podem variar para mais ou para menos nas diferentes combinações entre estes contextos. Como não é possível controlar por habilidades cognitivas, o efeito em particular da educação superior estaria superestimado e/ou o da origem de classe 
subestimado. Na origem no topo os retornos da educação superior, na comparação com o nível inferior, aumentaram nas duas coortes intermediárias e depois caíram na última coorte para um patamar abaixo da primeira coorte. A vantagem proporcional da origem no topo social era de 1,3867 no logaritmo do resultado na coorte de 48-57 e passou para 1,2667 na coorte de 78-87. A retração da vantagem proporcional foi de -0,1199 entre a primeira e a última coorte, porém esta vantagem, na verdade, pode ter mudado entre $-0,4286$ e $+0,1886$. No conjunto do período teria ocorrido uma flutuação sem tendência certa, tendo em vista as elevações dos retornos nas duas décadas intermediárias e a forte oposição entre os intervalos de confiança da estimativa. A vantagem proporcional da educação superior na origem de empregado qualificado passou por um processo similar. Ela era de 1,5527 no logaritmo do resultado na coorte de $48-57$ e passou para 1,2667 na coorte de 78-87. A retração desta vantagem proporcional foi de 0,1724 entre a primeira e a última coorte, porém esta vantagem, na verdade, pode estar variando entre $-0,4728$ e $+0,11281$. Não é certo afirmar que haja uma tendência de queda.

Os retornos da educação superior não são equivalentes entre as distintas origens. O topo social não mostra tendência inequívoca de queda enquanto a base social seguramente revela tendência declinante. Na origem de trabalhador típico a queda é contínua. O retorno para a coorte atual é inferior ao da primeira. A retração da vantagem proporcional da educação superior foi de -0,4458 entre a primeira e a última coorte, com intervalo de confiança entre -0,6763 e -0,2153. Já na origem de destituído ocorre uma tendência ainda mais forte de queda com estabilização na última coorte em um patamar bastante inferior. A retração da vantagem proporcional da educação superior foi de 0,5235 entre a primeira e a última coorte com intervalo de confianças 


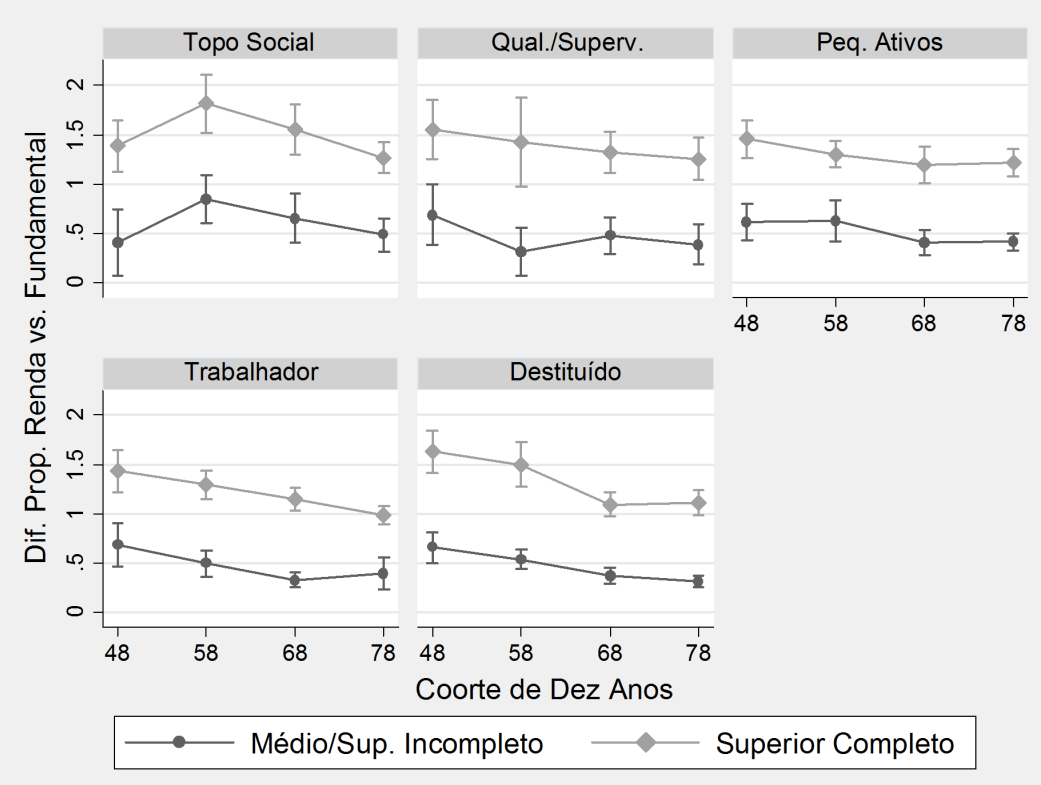

Gráfico 5. Diferença proporcional de renda entre níveis educacionais, por origem de classe e coorte, com intervalo de confiança de $95 \%$

entre -0,7634 e -0,2636. Por fim, a origem de pequenos ativos experimentou também uma tendência de queda. A retração da vantagem proporcional da educação superior foi de -0,2258 entre a primeira e a última coorte, com intervalo de confianças entre -0,4633 e +0,0116.

Os retornos do ensino médio mostram tendências semelhantes ao ensino superior. Para o destituído o limite inferior do intervalo de confiança da coorte 48-57 supera o limite superior da coorte 78-87. Neste critério o declínio de retornos é claro. A retração da vantagem proporcional do ensino médio foi de -0,3399 entre a primeira e a última coorte, com intervalo de confianças entre -0,5112 e -0,1686. Para as origens de trabalhado típico e de pequenos ativos a superposição dos intervalos de confiança ocorre somente nos extremos. A estimativa da 
mudança confirma uma retração da vantagem proporcional do ensino médio para o trabalhador típico de -0,2859 entre a primeira e a última coorte, com intervalo de confiança entre -0,5596 e -0,0121. Por fim, a retração da vantagem proporcional do ensino médio para a origem de pequenos ativos foi de -0,2437 entre a primeira e a última coorte, com intervalo de confianças entre -0,4788 e -0,0086. As diferenças encontradas e seus intervalos de confiança comprovam as tendências de queda dos retornos da educação para estas duas origens, pois a imprecisão diz respeito mais à dimensão desta retração.

\section{Discussão e conclusão}

Uma clarificação preliminar deve preceder o comentário das relações entre desigualdade e mobilidade social à luz dos resultados deste trabalho. A medida de renda no destino tem a vantagem de estar estreitamente correlacionada com as medidas canônicas de desigualdade de renda. A elasticidade não é afetada por alteração na renda média entre coortes; expressa uma mudança relativa, não absoluta. Entretanto, a elasticidade é sensível à variância das variáveis independente e dependente. Isto significa que ela é afetada pela extensão da desigualdade em cada coorte e pelas mudanças na desigualdade entre as coortes. $\mathrm{Ce}$ teris paribus, a elasticidade aumenta com o aumento da desigualdade e vice-versa (TORCHE, 2015a, p. 44; TORCHE, 2015b, p. 349). O estudo usou uma medida de semi-elasticidade que é um híbrido de efeitos marginais e elasticidade (CAMERON, TRIVEDI, 2009, p. 335). Foi estimada a mudança no logaritmo da renda (mudança proporcional ou elasticidade) associada a cada mudança discreta na categoria de origem de classe. As categorias de classe não são afetadas diretamente pelo nível da desigualdade de renda na origem, pois não são 
baseadas em renda. O resultado não é afetado diretamente pelas $m u$ danças na desigualdade de renda entre as coortes, pois a renda não foi medida na origem e comparada na mesma métrica com o destino. Entretanto, as categorias de classe estão associadas à estrutura da desigualdade de renda e implicam distâncias relativas de renda entre as categorias. Além disso, supõe-se que o resultado seja afetado pelo nível de desigualdade existente no destino em que a renda está sendo mensurada.

Os Gráficos 1 e 2 mostram uma elevação da vantagem da origem no topo social nas coortes intermediárias quando o país tinha uma maior desigualdade de renda. A renda de todas as coortes está sendo medida em 2014 quando a desigualdade é menor. Entretanto, os contrastes entre os empregos dos pais no período anterior expressavam um grau maior de desigualdade. As coortes estiveram sob influência de contextos diferentes. Mantidos os demais fatores constantes, supõe-se que maior vantagem de origem importa mais. A questão mais complexa está justamente na transmissão intergeracional destas consequências. O efeito da origem é maior na coorte mais desigual em função mesmo desta desigualdade originária? Existe na literatura o argumento de que as relações entre desigualdade e mobilidade dependem na verdade de fatores que moldam ambas as dimensões, como arranjos institucionais e configurações de regimes de bem-estar. Se isto for verdade, então, a relação seria espúria (TORCHE, 2015, p. 353355). Uma relação é espúria quando duas variáveis estão associadas entre si simplesmente porque ambas estão associadas a uma terceira variável sem que exista um nexo intrínseco entre elas. O problema com este argumento é que nem a estrutura da desigualdade nem os arranjos institucionais do passado são os mesmos do presente. A terceira variável “arranjos institucionais” não está de fato em tempora- 
lidade equivalente ou próxima da mesma coorte para estabelecer a associação espúria. Fatores supervenientes podem naturalmente afetar a transposição da desigualdade de uma coorte em oportunidades desiguais entre os filhos. Os efeitos dos fatores antecedentes podem ser mediados ou alterados por fatores supervenientes que afetam a transmissão das vantagens. Variáveis mediadoras ou moderadoras têm pressupostos diferentes das relações espúrias. A noção de mediação, ao contrário da relação espúria, supõe o poder causal do efeito primário ou original e um intervalo temporal em que se dá a transmissão indireta do efeito. É plausível que a maior desigualdade originária possa ter influenciado a trajetória da coorte até o presente. Estando certa esta premissa, isto significa que a desigualdade passada persiste ou repercute nas posições relativas ocupadas na distribuição da renda presente. Além disso, no caso concreto do Brasil, os arranjos institucionais, como uma dimensão distinta das mudanças estruturais, regra geral não têm atuado historicamente em uma direção equalizadora ponderável sobre a desigualdade de origem.

O nível relativamente menor de desigualdade de renda em 2014, quando a renda dos filhos foi medida, produziria uma medida esperada menor de associação intergeracional em particular na última coorte. Afinal, a medida usada é afetada pelo nível da desigualdade. Isto seria uma “deficiência” da medida, quando se pensa na mobilidade relativa ou associação líquida, que desconsidera a mudança estrutural ou distributiva no destino. Entretanto, esta propriedade da medida representa uma qualidade quando se está interessado no papel do nível da desigualdade na trajetória que emerge do jogo entre mudanças estruturais. De fato, a vantagem do topo sofre uma redução entre a penúltima e última coorte. Os membros da penúltima coorte nasceram entre 1969 e 1977. O emprego dos pais foi medido quando os filhos 
tinham 15 anos. Isto corresponde ao período de 1984 a 1992 que sofre o impacto da crise dos anos 1980 e da hiperinflação. O fato de a vantagem da origem no topo ter atingido o seu ponto máximo nesta coorte pode estar associado a este contexto. Isto supõe que o estiramento da desigualdade cria uma espécie de dependência de caminho ou transposição durável de feitos. A queda posterior ocorreria naturalmente na medida em que a vantagem do topo chegou ao seu ponto máximo. A vantagem do topo não mostra uma tendência de redução na comparação entre a primeira e a última coorte. Os integrantes da primeira coorte nasceram entre 1948 e 1957. O emprego dos pais foi medido no período de 1963 a 1972. A desigualdade de renda era então bem maior do que na atualidade. O nível de desigualdade entre os pais e o contexto em que ela ocorre parece importar para a mobilidade dos filhos. Maior desigualdade no passado pode afetar a trajetória dos filhos. Menor desigualdade no presente não implica necessariamente em maior mobilidade dos filhos, independente do passado. Uma menor desigualdade de renda não se associou a uma menor transmissão intergeracional de vantagens no Brasil. A vantagem proporcional da origem classe mais privilegiada mostra-se ainda mais marcante e robusta por estar sendo medida em um contexto de menor desigualdade de renda.

Olhando para a renda dos filhos não se constata um processo equalizador das oportunidades de mobilidade social no Brasil. A origem privilegiada no topo social garante renda mais elevada para os filhos e se destaca em relação a todas as demais origens. Em particular, o efeito direto de origem é bastante alto. Na origem de empregado qualificado e supervisor, embora a renda predita dos filhos seja menor, em relação a quem vem do topo social, o efeito direto de origem é ainda mais alto. Garante mais renda do que as posições abaixo na hierarquia 
social; garante menos que o topo, porém com mais certeza.

Nas demais origens de classe, além da renda predita ser bem menor, um processo diferenciado se estabelece. Na origem de trabalhador típico a mediação educacional quase não afeta a renda predita. Estando em um nível próximo do mediano, dada a relação entre origem e realização educacional, a educação parece não comprometer nem potencializar a renda dos filhos. Nos demais agrupamentos de origem a renda predita seria maior, se não fossem as desvantagens educacionais que possuem. Entretanto, dados os limites dos empregos onde foram parar, os ganhos seriam somente $17 \%$ maiores do que são, se a escolaridade mais baixa não fosse um estorvo. Mesmo se isto tivesse ocorrido, ainda assim as rendas deles estariam abaixo dos ganhos daqueles que vieram da origem de empregado qualificado e supervisor. O controle adicional da posição de classe atual, medida pela tipologia plena, basicamente aumenta os resultados constatados para a origem no topo e de empregado qualificado. Destaca-se o fato de o efeito direto da origem no topo permanecer bastante alto após este controle. Em parte, isto pode decorrer do fato de se estar medindo a alteração do resultado na renda predita. As rendas de determinados tipos de empregos, em particular se forem privilegiados, possuem certa base ou limiar mínimo que contém variações na direção de valores mais baiXos.

A questão do papel equalizador da educação, no curso dos processos de modernização e expansão educacional, envolve criticamente a observação das tendências que emergem entre as coortes. Na origem no topo social a vantagem total em relação ao agrupamento destituído mostra-se estável e o efeito direto não revela uma tendência de queda entre as coortes. Se alguma alteração temporal ponderável ocorreu na mobilidade social, quando medida pela renda dos filhos, ela se deu 
entre categorias próximas ou menos distantes da base social.

Supõe-se em parte da literatura que a educação superior poderia estar concentrando o papel equalizador da educação nas circunstâncias contemporâneas. A manifestação mais patente disto seria o enfraquecimento do efeito de origem neste nível educacional. Entretanto, as interações entre classe de origem e níveis educacionais não confirmam esta expectativa no Brasil. A origem no topo social gera mais vantagem em quem tem curso superior completo e é alta nos dois outros níveis educacionais. A origem no topo social conjuga os benefícios, tanto dos processos ofensivos, quanto dos defensivos, usados pelos atores na transmissão intergeracional de vantagens. A escolaridade superior potencializa a renda de quem cumpre uma esperada trajetória educacional exitosa. A herança social privilegiada garante igualmente uma vantagem de renda apreciável para a minoria entre os pares que fracassa ou fica bastante aquém do potencial de realização educacional dado pela origem familiar.

O papel da educação na transmissão de vantagens de origem social depende da desigualdade de oportunidade educacional e do valor econômico da educação (HOUT, 2012). A transmissão intergeracional de vantagens, na medida em que é mediada pelas institucionais educacionais, supõe que os retornos da educação mais elevada são apreciáveis. Neste aspecto, o aumento da desigualdade de oportunidades está associado ao aumento dos retornos educacionais entre as coortes. O estudo constata uma queda entre a primeira e última coorte, tanto dos retornos da educação superior, quanto do nível médio de ensino completo. A defasagem absoluta foi maior na educação superior e a relativa na educação média. A queda é contínua desde a segunda coorte para a educação superior. O processo teria uma implicação favorável para a igualdade de oportunidades se ele estivesse afetando 
em particular quem tem vantagens de origem. Se a queda fosse igual para todos ainda assim a origem privilegiada poderia ter perdas, pois grande parte dos seus descendentes obtém este nível de educação e converte ele em melhores empregos.

As interações entre origem, coorte e educação não mostram um quadro propriamente desfavorável para a origem no topo social, pois não é certo que os retornos da educação superior estejam caindo para ela. Mesmo supondo que todos possam estar sendo afetados por este processo, em alguma medida, ainda assim esta origem estaria neutralizando ou compensando o resultado por outros mecanismos. Subjacentes aos resultados sociais observados podem operar tendências e contra tendências. Por outro lado, o rebaixamento comparativo dos retornos da educação superior é inequívoco na base social composta do trabalhador típico e do leque de posições destituídas de ativos. A expansão educacional no período, além de ter sido desigual na distribuição dos ganhos de educação, se associou a uma queda dos retornos proporcionais, tanto da escolaridade superior, quanto do ensino médio, para quem possui menos e depende mais do recurso educacional na realização de oportunidades de vida.

Olhando a partir do topo social um estudo anterior não confirmou a vigência de um processo equalizador das oportunidades de mobilidade social no Brasil. A realização socioeconômica foi medida em termos da probabilidade de acesso ao topo social (FIGUEIREDO SANTOS, 2019). Embora esta seja uma questão crítica nos estudos de mobilidade social, não estavam sendo considerados os fluxos nos demais âmbitos da estrutura social abaixo do topo. Este estudo considera como resultado final a renda de todas as fontes. Trata-se de uma medida mais abrangente em termos de cobertura e capaz de captar gradações nos resultados. As duas medidas podem ser vistas como 
complementares. $\mathrm{O}$ acesso ao topo social focaliza a fronteira decisiva em que operam os principais mecanismos de vantagens de classe social, ou seja, propriedade, autoridade e conhecimento perito. A renda como destino retrata como o efeito de origem pode oferecer mais ou menos de algo valioso. Capta potencialmente deslocamentos que podem ocorrer em um espectro que abarca, mas não se limita aos ricos. Regra geral, os dois estudos mostram resultados convergentes nas quatro questões comuns que foram investigadas. O efeito total e o efeito direto da origem, as tendências entre as coortes, os efeitos da origem por níveis educacionais, os padrões de retornos da educação, os retornos da educação por classe de origem, considerados em conjunto, não confirmam uma tendência de enfraquecimento das desigualdades de oportunidades no curso do jogo entre mudanças estruturais. As vantagens de origem continuam a gerar no destino vantagem de chances de vida na sociedade brasileira em meio às mudanças estruturais e seus efeitos no decorrer da sucessão de coortes.

\section{Referências}

BALDWIN, Scott A.; FELLINGHAM, Gilbert W.; BALDWIN, Austin S. Statistical models for multilevel skewed physical activity data in health. $\mathrm{He}$ alth Psychology, v. 35, n. 6, p. 552-562, 2016.

BALLARINO, Gabriele; BERNARDI, Fabrizio. The intergenerational transmission of inequality and education in fourteen countries: a comparison, in: BERNARDI, Fabrizio; BALLARINO, Gabriele (ed.). Education, Occupation and Social Origin. Cheltenham: Edward Elgar Publishing, 2016. p. 255-282.

BERNARDI, Fabrizio; BALLARINO, Gabriele. Education, occupation and social origin: a comparative analysis of the transmission of socioeconomic inequalities. Cheltenham: Edward Elgar Publishing, 2016a.

. Introduction: Education as the great equalizer: a theoretical frame- 
work, in: BERNARDI, Fabrizio; BALLARINO, Gabriele. (ed.). Education, occupation and social origin. Cheltenham: Edward Elgar Publishing, 2016b. p. 1-19.

BREEN, Richard; LUIJKX, Ruud. Conclusions, in: BREEN, Richard (ed.). Social mobility in Europe. Oxford: Oxford University Press, 2004. p. 383410.

CAMERON, A. Colin; TRIVEDI, Pravin K. Microeconometrics using Stata. College Station: Stata Press, 2009.

DUNN, Christopher. The intergenerational transmission of lifetime earnings: evidence from Brazil. The B. E. Journal of Economic Analysis \& Policy, vol. 7, n. 2, (Contributions), Art. 2, p. 1-40, 2007.

ERIKSON, Robert; JONSSON, Jan O. Social origin as an interest-bearing asset: family background and labour-market rewards among employees in Sweden. Acta Sociologica, v. 41, n. 1, p. 19-36, 1998.

HANSEN, Marianne. Education and economic rewards: variations by social class origin and income measures. European Sociological Review, v. 17, n. 3, p. 209-31, 2001.

HÄLLSTEN, Martin. The class-origin wage gap: heterogeneity in education and variations across market segments. The British Journal of Sociology, v. 64, n. 4, p. 662-690, 2013.

HARDIN, James; HILBE, Joseph. Generalized linear models and extensions. 3. ed., College Station: Stata Press, 2012.

HOUT, Michael. Social and economic returns to college education in the United States. Annual Review of Sociology, v. 38, p. 379-400, 2012.

FIGUEIREDO SANTOS, José Alcides. Estrutura de posições de classe no Brasil. Belo Horizonte, Editora UFMG, 2002.

. Uma classificação socioeconômica para o Brasil. Revista Brasileira de Ciências Sociais, v. 20, n. 58, p. 27-45, 2005.

. Comprehending the class structure specificity in Brazil. South African Review of Sociology, v. 41, n. 3, p. 24-44, 2010.

. Esquema de classe para abordar a desigualdade de saúde no Brasil. In: ROSENBERG, F. (Org.). Classes sociais, território e saúde: questões metodológicas e políticas. Rio de Janeiro: Editora Fiocruz, 2014. p. 39-59. 
Disponível em: www.forumitaborai.fiocruz.br.

. Classe social e deslocamentos de renda no Brasil. Dados - Revista de Ciências Sociais, v. 58, n. 1, p. 79-110, 2015.

. Origem de classe e destino ao topo social no Brasil. Revista Brasileira de Sociologia, v. 7, n. 16, 2019.

GOLDTHORPE, John. Social class mobility in modern Britain: changing structure, constant process. Journal of the British Academy, v. 4, p. 89-111, 2016.

LONG, J. Scott; FREESE, J. Regression models for categorical dependent variables using Stata. 3. ed. College Station: Stata Press, 2014.

PETERSEN, Trond. Multiplicative models for continuous dependent Variables. Sociological Methodology, v. 47, n. 1, p. 113-164, 2017.

RIBEIRO, Carlos A. Occupational and income intergenerational mobility in Brazil between the 1990s and 2000s. Sociologia \& Antropologia, v. 7, n. 1, p. 157-185, 2017.

SCHENKER, Nathaniel; GENTLEMAN, Jane F. On judging the significance of differences by examining the overlap between confidence intervals. American Statistician. v 55, n. 3, p. 182-186, 2001.

TORCHE, Florencia. Intergenerational mobility and inequality: the Latin American case. Annual Review of Sociology. v. 40, p. 619-42, 2014.

Analyses of intergenerational mobility: an interdisciplinary review. The ANNALS of the American Academy of Political and Social Science, n. 657, p. 37-62, 2015a.

TORCHE, Florencia. Intergerational mobility and equality of opportunity. European Journal of Sociology, v. 53, n. 6, p. 343-371, 2015b.

VANDECASTEELE, Leen. Socio origin, education and socio-economic inequalities: trends in the United Kingdom, in: BERNARDI, Fabrizio; BALLARINO, Gabriele. (ed.). Education, occupation and social origin. Cheltenham: Edward Elgar Publishing, 2016.

VITTINGHOFF, Eric et al. Regression methods in biostatistics. 2 ed. New York: Springer, 2014.

WEBER, Max. Economia e sociedade: fundamentos da sociologia compreensiva. vol. 2. Brasília: Editora Universidade de Brasília, 2004. 
WRIGHT, Erik Olin. Class counts: comparative studies in class analysis. Cambridge: Cambridge University Press, 1997. 


\section{Resumo:}

O trabalho investiga as relações entre origem de classe e chances de vida no Brasil com os dados de mobilidade social da PNAD 2014. Os efeitos da origem foram estimados sob a forma de médias preditas e diferenças proporcionais na renda com um Modelo Linear Generalizado. A magnitude e a evolução entre as coortes dos efeitos totais e diretos da origem privilegiada na renda colocam em questão o papel equalizador da educação. A origem no topo social, tanto impulsiona a renda de quem tem escolaridade superior, quanto protege quem fracassa na escola. Os retornos da escolaridade superior e média estão caindo entre as coortes. Esta queda afeta quem tem origem na base social, porém não no topo social. Maior desigualdade originária parece favorecer a vantagem de origem. A menor desigualdade de renda atual, no entanto, não reduziu a vantagem de origem entre a primeira e a última coorte.

Palavras-chave: Classe social; mobilidade social; origem social; chances de vida; renda. 


\begin{abstract}
:
The paper investigates the relationships between class origins and life chances in Brazil with PNAD 2014 social mobility data. The effects of the origin were estimated as predicted averages and proportional differences in income with a Generalized Linear Model. The magnitude and the evolution between the cohorts of the total and direct effects on income of the privileged origin question the equalizing role of education. The origin in the social top both boosts the income of those who have higher education and protects those who fail in school. The returns of upper and middle schooling are falling among the cohorts. This fall affects who originates in the social base, but not in the social top. Greater original inequality seems to favor the advantage of origin. The lower present-day income inequality, however, did not have reduced the advantage of origin between the first and last cohort.
\end{abstract}

Keywords: Social class; social mobility; social origin; life chances; income. 